
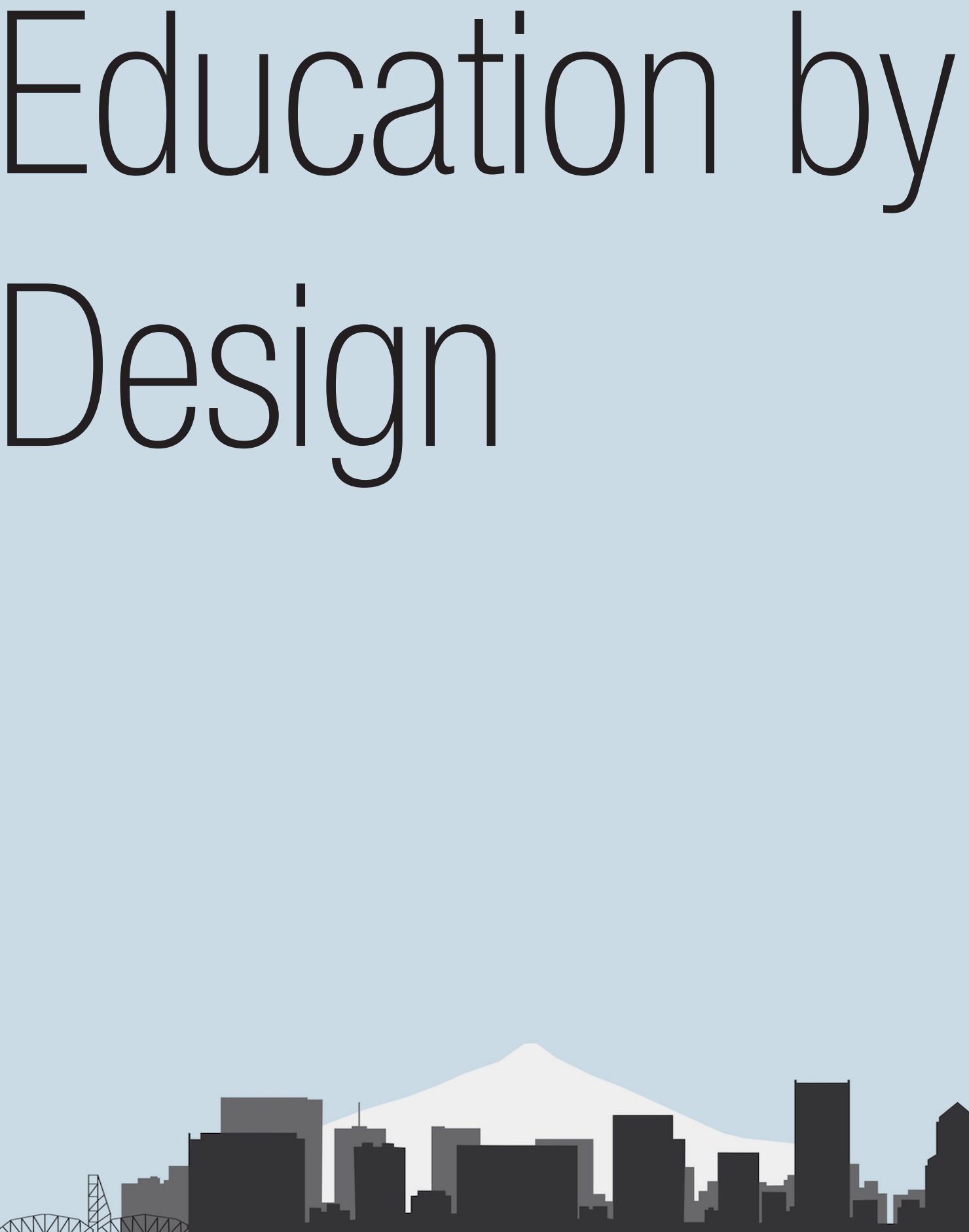

2019 Reynolds Symposium: Education by Design October 18-20, 2019 


\section{Organizing Committee:}

[co-organizers]

Professor Alison Kwok, Ph.D, FAIA, University of Oregon

Emeritus Professor John Reynolds, FAIA, University of Oregon

\section{[Symposium coordinator]}

Isabel Rivera, Ph.D., University of Oregon

Professor Walter Grondzik, P.E., Ball State University

Professor Bruce Haglund, AIA Assoc., University of Idaho

Assistant Professor Emily McGlohn, AIA, Auburn University

Associate Professor Ulrike Passe, lowa State University

Assistant Professor Siobhan Rockcastle, Ph.D., University of Oregon

Sharon Refvem, FAIA, LEED Fellow, Senior Associate and Director, Sustainability Resource Group, Hawley Peterson Snyder 


\title{
Beyond Sustainability: Architectural Education in an Ever-Changing Climate
}

\author{
Peter S. Raab, Architect \\ Associate Professor \\ Texas Tech University \\ Lubbock, Texas \\ peter.raab@ttu.edu
}

\begin{abstract}
Within a rapidly changing climate, never have humans seen such rampant degradation of their environment. From water shortages and over-population to massive flooding and storms, we are beginning to test strategies of resilience at the urban and architectural scale. With the scientific evidence of our warming climate system being unequivocal, design professionals must be cognizant of the impact of these changes on theory, pedagogy, and practice. An integrated and resilient approach to ecological design of buildings, landscapes and communities within this changing climate is imperative. Too often we teach students to look solely at technological means as the solution to our ailing building design, however it is important to understand precise constraints of climate to produce rigorous design solutions. This starts with a knowledge of larger environmental systems.
\end{abstract}

This paper will outline a three-pronged approach recently employed to ensure undergraduate design students grasp larger frameworks impacting the future of architectural practice within the Anthropocene. Using varied modes of interrogation, students are required to delve more deeply into a series of analytical exercises developed collaboratively to elicit thoughtful, appropriate and responsible massing, orientation and material strategies throughout the sequence. By designing an extensive framework beyond the simplistic, superficial separatism of modernism, the designer is enabled to understand architecture as in an open-exchange with the larger bioclimatic, social and ecological worlds.

\section{INTRODUCTION}

Beginning in modern history, the architecture school at the dominant École des Beaux-Arts, classical architectural orders, proportion and formal systems were the focus. From its founding in 1648, the classically-derived educational system established in France reverberated across the globe. In addition to the 'beautiful' stylistic and representational work, we also see for the first time a clear division between architecture and engineering within the professional curricular structure into Beaux Arts and Polytechnic schools. This split model was adopted as the basis for architectural education until the early twentiethcentury. Even with the introduction of the German Bauhaus during the 1920's and 1930's, this separation is still present, if not emphasized within the push for 'modern' architectural style. If the Beaux-Arts divided technical from the art, the Bauhaus and the search for an International Style of architecture derived its language from the modernist frame of separating man from nature while promoting the architectural object and international style. As early as the 1940's and 1950's more regional approaches to adapting these competing international styles to specific geographic and climatically-diverse territories exemplified in Aalto's work in Finland and the Saarinen in the United States, among others. During the annual meeting of the Association of Collegiate Schools of Architecture in Grand Rapids during the winter of 1949, Buford L. Pickens, then Head of the Department of Architecture at Tulane University wrote of a desire for "regional possibilities in design and construction research." (Pickens 1949, 20) He further elaborates on the potentialities of 'organic' ways of planning and design that address geographic and cultural frameworks that are "especially important for schools of architecture..." in how they could allow a "new kind of integration for research in history, design and construction." (Pickens 1949, 20) This open call for an adaptative architectural education recognizes buildings as a part within a larger whole as 
opposed to the modernist proclivities of 'sectionalism' and 'isolation' which attempt to divide architectural design from its larger context, climate and culture of the place. (Pickens 1949)

Victor Olgay's 'Design with Climate', released in 1963, continues this trend towards a more attuned architectural strategy tied to specific regions within the United States. Several schools have grafted on more environmental approaches to design, culminating in the addition of sustainable design programs throughout the United States and Europe in the 1990's and early 2000's. More recently, Alberto PerezGomez' 'Attunement' broadly places the German concept of Stimmung - attunement - at the center of architecture's connection to a specific place, over the more modern conception of space. (Perez-Gomez, 2016). Sustainability misses the mark by being too anthropologically scaled, as it deals with buildings in isolation from their environment and on a case-by-case basis often ignoring larger ecological and environmental problems for the technological 'band-aid' on the larger axe-wound of material shortages, climate-change and ecological degradation. To re-build the world more 'sustainably' is simply not an option for the fact that the material resources required, coupled with expected population growth would require "several planets" (Latour 2018, 5). Common practices in architectural design and building bring together materials from across the world to create 'sustainable' buildings, but at what cost to the sourcing, production and transportation expenditures of global building design. In "The Hierarchy of Energy in Architecture: Emergy Analysis," Ravi Srinivasan and Kiel Moe unpack the ideas of emergy as a way to convey the true energy and material costs of constructing a contemporary building (Srinivasan and Moe 2015). Using an ecological frame to understand both the impacts of architectural design not only on human health, but also on the larger landscape and region is essential to design student's today. As Dipesh Chakrabarty so eloquently stated, "The future emerges directly from the objects we design" (Graham 2016, 23). We need to raise awareness and curiosity within today's design students to grapple with the very real ramifications of design interventions on our world - beyond the false dichotomy of nature and humans. "The image of green supersedes the actual environmental performance of green much the same way that the modernists' aspirations for buildings as efficient and hygienic machines became an alibi for adopting the look of the machine..." (Schafer and Lawrence 2011, 4).

Throughout the history of architectural pedagogy, architecture schools, faculty and even students have given rise to new methodologies of architectural thought, instruction which then rippled through the discipline. Not as something merely stylistic or eclecticism, but a pedagogy that could truly "Radical pedagogies shake foundations, disturbing assumptions rather than reinforcing and disseminating them." (Colomina et al. 2012) The 1968 student revolts of the Unité Pédagogique No 6 in Paris, rejecting specifically the Beaux-Arts pedagogy that was "incapable of addressing architecture's relationship to contemporary social and political maladies" was a significant event. (Colomina et al. 2012) Revolts in the late sixties happened within architecture schools throughout the world, as students demanded a curriculum that more reflected their aspiration for a new social order. Notably was the burning of the School of Art and Architecture at Yale in 1969, likely by the students themselves. Within the essay "Radical Pedagogies in Architectural Education" by Beatriz Colomina and several others, several varied examples of architectural education being used as a platform to reformulate the discipline from it's very foundations to 'destabilize social, political, economical or technological conventions." (Colomina el al. 2012) Can we not use the overwhelming evidence that with $\mathrm{CO}_{2}$ PPM climbing at an unprecedented rate, and anthropogenic climate-change becoming a globally as a flashpoint to begin to radically change our current architectural models? How can we create a radical pedagogy for our times?

\section{THREE-PRONGED APPROACH}

While many of these approaches have honest intentions and significant results both speculative and built, more complete, ecological notions of architectural thought and design need to be embedded more deeply and thoroughly into the curriculum from first-year onward. As Dipesh Chakrabarty stated in conversation with James Graham in Climates, we need to move beyond anthropocentric-minded thinking if we are to prosper in the new millennium by not 'imagining ourselves at the center of things.' (Graham 2016, 23) While architecture is ostensibly for humans, how can educators commence design education to position ourselves within the world beyond the walls, considering more open systems that are in actively exchange with our environment - as buildings inevitably do? 


\section{Contextualizing Contexts}

Moving beyond a simple insertion of a class or two, a re-writing and re-structuring of the entire curriculum to approach design with climate more holistically throughout the undergraduate design studies is needed to prepare students for architectural building design in the $21^{\text {st }}$ century as no other time in human history has climate change been so relevant to our future on this planet. Beyond our anthropomorphic lens which views all non-humans as material and products for our consumption, we must adapt a broader scope in which architectural solutions consider an ecological awareness.

Teaching students to use analytical tools to process complex environmental data to better inform designs is imperative for a more holistic education of how architecture places ourselves in the world. In 2009, during the Society of Building Science Educators (SBSE) proposed to the National Architectural Accrediting Board (NAAB) and the Canadian Architectural Certification Board (CACB/CCCA) set a condition for accreditation that every North American architecture school provide both theoretical and practical knowledge of design of carbon neutral/ net-zero building within the curricula. Although this suggestion was rejected, it is still important for preparing future architects and designers to design resilient and climate-tuned projects (La Roche 2018). Each school, especially state-schools whose directive is to train future architects for the profession of architecture should develop graduate students who understand the fundamentals of bio-climatic design - especially for the region(s) that these future architects will design buildings within. One of the important aspects of the Olgyay's 'Design with Climate' was how they translated from early modernism a design methodology that first understood the bioclimatic region to develop designs that were attuned to the place (Olgyay 1961). This attunement should begin with the understanding of humanistic qualities of space and place, material and light, environment and climate, and build to a more technical, integrated and disciplinary-based curriculum upon graduation. Underlying this push is a need for our students to have a more empirical understanding of how the world works - from thermodynamics to gravity and the sun - and how these seemingly straightforward elements can be quite weighty and lead to deeper architectural ideations that are able to adapt and thrive to a changing climate and be tuned to the larger surrounds.

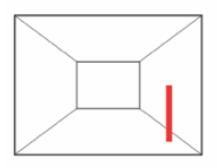

space [fall] $\ldots$ OEAR $\ldots$

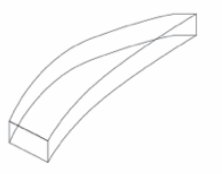

form(ation)

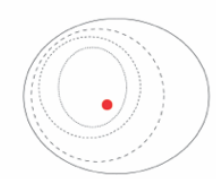

place

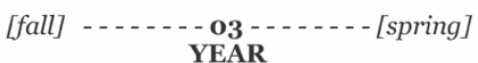
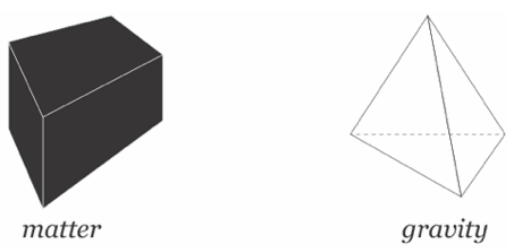

[fall]

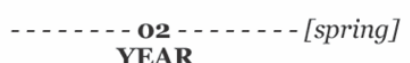

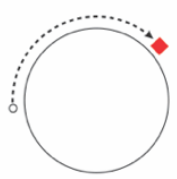

external culture

[fall]

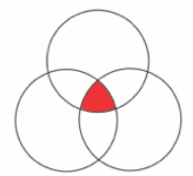

integration

Figure 1. Simplified diagram of design studio sequence as related to climates and ecologies Source: Author, 2019.

This paper will explain the development of the three different sequences; Design Studio Foundation, Collaboration between Technology and Design, and finally Integration and Topical Studios. Each section will outline a specific example of a project, how it has evolved and the relevant discoveries associated with student learning objectives. We can see within Figure 1, how the focus from one semester to the next 
grades up in scale and inherent complexity. Each course within the year, whether it be History/Theory, Representation, Technology or Studio frame the content delivery in relation to these themes.

\section{Adapt or Deny}

A scalar approach to the design studio and technology sequence and how our College is positioning itself within the University and territory as a knowledge center to respond to climate change. A changing climate will affect ecosystems, built environments and human health in addition to existing social, cultural, institutional, and political arrangements. We can adapt, or deny and defer, but more resilient methods of education of an architect to adapt to indeterminant futures is imperative. Going beyond the walls of the College of Architecture, whilst creating cross-campus links to other disciplines are essential. Within the curricular structure, the design studio offers a unique opportunity to synthesize complex and disparate subjects through the iterative and speculative process. The sequence is manifold from first-year through fourth-year coursework, each building in specificity in notions of material, ecology, and sustainability. Using a systems ecology model of looking at the process of construction and "emergy" flows to consider materials through the direct (and indirect) energy available to make architectural product as outlines a specific thrust of our pedagogy to use thermodynamics as a more efficient design methodology to convey heat and coolth from the surrounding environments through material choices, insolation and orientation (Srinivasan and Kiel Moe, 2015). We introduce ideas of temporal environments to better convey larger frames from which the territory, culture, and ecology effect architectural design. These topics are introduced within the first-year and reinforced through each of the subsequent studio prompts.

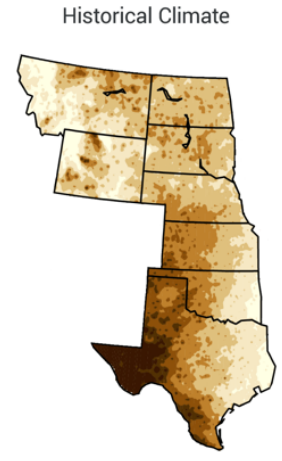

Number of Consecutive Days

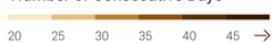

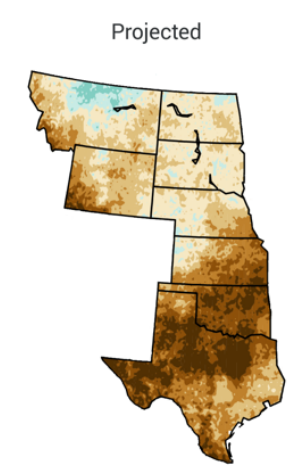

Change in Number of Consecutive Days
Historical temperature on the 7 hottest days of the year
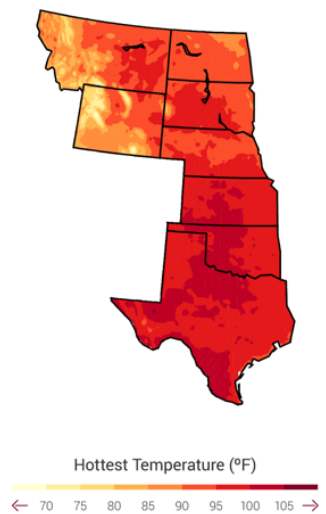

Projected

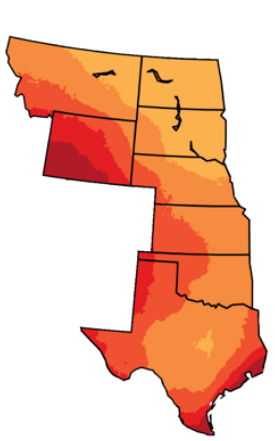

Change in Number of Days

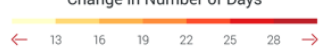

Figure 2. Current regional trends of a drier south and a wetter north are projected to become more pronounced (left) and the number of days with the hottest temperatures project to increase dramatically by mid-century, 2041-2070. Source: NOAA/NCDC/CICS-NC, 2019.

While it might seem counter-productive to begin an introductory design course in architecture with discussions about a changing climate, especially within the current polarized and politicized climate, there are ways to more covertly introduced how geographic, atmospheric and climatic tendencies have shifted over time. Lubbock's location on the Ogallala aquifer; one of the world's largest in the world with an area approximately 174,000 square miles in portions of eight states and provides drinking water to $82 \%$ of the 2.3 million people residing above it (Dennehy 2000). With current expectations that the water will run out between 15 and 50 years, planning now for an indeterminate future is only sane. As one of the only architecture school located within the area of the Dust Bowl, which was the last mass migration event in the United States, how can an architecture curriculum address notions of the current climate change, desertification of our landscape, the drying of the aquifer, or the distinct possibility of another mass migration within this century? "Adaptation actions can be implemented reactively, after changes in climate occur, or proactively, to prepare for projected changes...” (NRC 2010). 


\section{Design Studio Foundation}

First year considers several aspects of how to think and represent ideas through drawing, modeling and speaking. Stuff matters, and students can combine their perceptual knowledge of the heat, dust and the phenomena of different materials within the first year. The first semester mainly deals with foundational concepts of 'why' and 'how' while introducing the premise of architecture through history, theory and precedent study with special attention spent on relating time and place of architectural thought and practice as it relates to exemplary works. Students work in drawing (project one), plaster (project two) and tectonic elements (project three), as they gain an architectural vocabulary. The second semester builds on the fundamental knowledge of space-making into a more refined study of making a place. Solar geometry and specific site context is offered as a crucible to locate their ideas within the ecological realm. This is one semester before the 'technology sequence' commences, but solar energy, and how sunlight can be used as a material to carve stereotomic form as well as introduce tectonics as a way to form space at a fundamental level. The site has a specific orientation along a canyon wall, where students must consider views to the west, uneven ground and location of the building in relation to a sloping site - something foreign to most of these students of the plains. Regional examples of the Anasazi cliff dwellings, Plains Apache tipi and wickiup, and Navajo hogan structures, along with early settlers dugout structures and more modern case studies are used to speak of interventions within a variety of climates with a focus on local and historic examples while testing the students pre-conceived notions of architectonic necessity. Coupled with this studio is the first history class which begins with regional architects that pre-date industrialized building processes and products that connect place and culture. Introducing these concepts within a heavily coordinated first-year studio structure instigates an understanding of context, climate and ecology and primes the more advanced questions that are raised in the subsequent years of the undergraduate sequence.

\section{Second-Year and the Technology Sequence}

Within the second-year, the technology sequence begins with an investigation into materials and matter, and traces geographic and ecological footprint of architectural elements brick, wood, steel, concrete and glass. Introducing material geography as well as what a localized ecological footprint might look like and the importance of carbon sequestration. These larger ideas of matter, material and how diurnal temperature swings, thermodynamics and solar energy might are considered when choosing from a variety of materials. Instruction of how material assemblies occur in historic and modern times is reinforced through a series of hands-on workshops. Essential to the development of this sequence is to go beyond insular calculations and details. Three such examples of this more extensive approach to the Building Technology Courses Students are noted below.

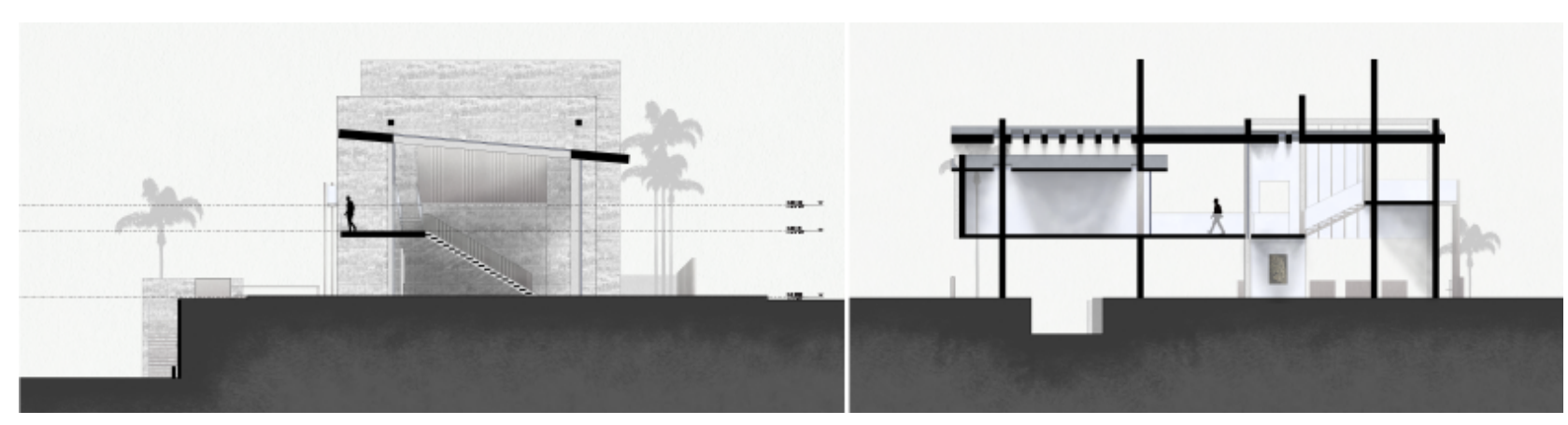

Figure 3. Final sectional drawings of second-year, fall semester project where students begin to employ materiality, thickness, light and shadow within a small, coastal condition where resilience, temporality and material/energy flows are synthesized. Brinton Freeze, fall, 2018.

During the first semester, second-year undergraduate, students are exposed to a range of materials, methods of construction and their sources - the 'why' always being a precursor underlying the 'what' and 'how'. Students are asked to purchase a four-foot long '2x4' and bring it to class. From this real understanding of the tangible product, students are then asked a series of questions that move from the 
visible to the invisible as discussion slowly zooms in to the molecular level of the wooden product, comparing this wood to others in density and defects, to growth rings, how water moves through the cellular structure, lignin and cellulose components and how these might resist water, tension, compression or decay. Once the miniscule is discussed, we zoom back out beyond the ' $2 \times 4$ ' to other milled lumber and composite types and backward through the industrialized process to the scope of the forest, solar energy, life-cycles, transportation and material geographies and transforming ecologies and climates. This conveys a total understanding of the material. As our school of architecture is located within a grassland on the American Great Plains, where previous to settlement there were no trees within the landscape this lesson is important in understanding where something so ubiquitous today has a long history as a building material. Of course, this exploration works out over the course of two weeks, as the students are asked to perform operations on a '2x4' by cutting, drilling, bending, breaking, mending and testing their stick. These types of explorations are similar when a new material or assembly is introduced such as a brick, concrete, mud blocks and metal building up in scale and complexity until the final project of creating a diagrammatic wall assembly. These assignments are loosely aligned with the second-year studio. The design studio begins to investigate matter and form as questions of site, orientation and climate are acclimated through architectural intervention. Questions of tectonics, material (thickness) and aperture (sun/wind) and path (orientation) within the site are answered through application of their knowledge of material assemblies and reinforce architecturally the student's ideas from first-year. During the second semester, architectonic assemblies begin to gain more sophistication as gravity, tension, compression and energetic forces are questioned and applied both within the technological sequence as well as the studio. The scale of the architectural project also is enlarged to move the students beyond the simple load-bearing and cellular types of construction to move considerations of materials and structures for strength and efficiency in addition to their ecological and carbon components.

Architect and educator Bryan MacKay-Lyons sums up the approach taken to teaching complex and technical issues within the College, especially in the undergraduate sequence. "Pragmatism is the best teacher. Learning is accelerated by purpose. We learn best when we need to know: technology is best understood by making; sequence is best understood when there is little time; teamwork is learned quickly when there is too much to do; topography is most apparent when we set the height of the platform" (MacKay-Lyons 2008). We can see this demonstrated within the second-year of the technology sequence, taking a design-build approach to conveying information.
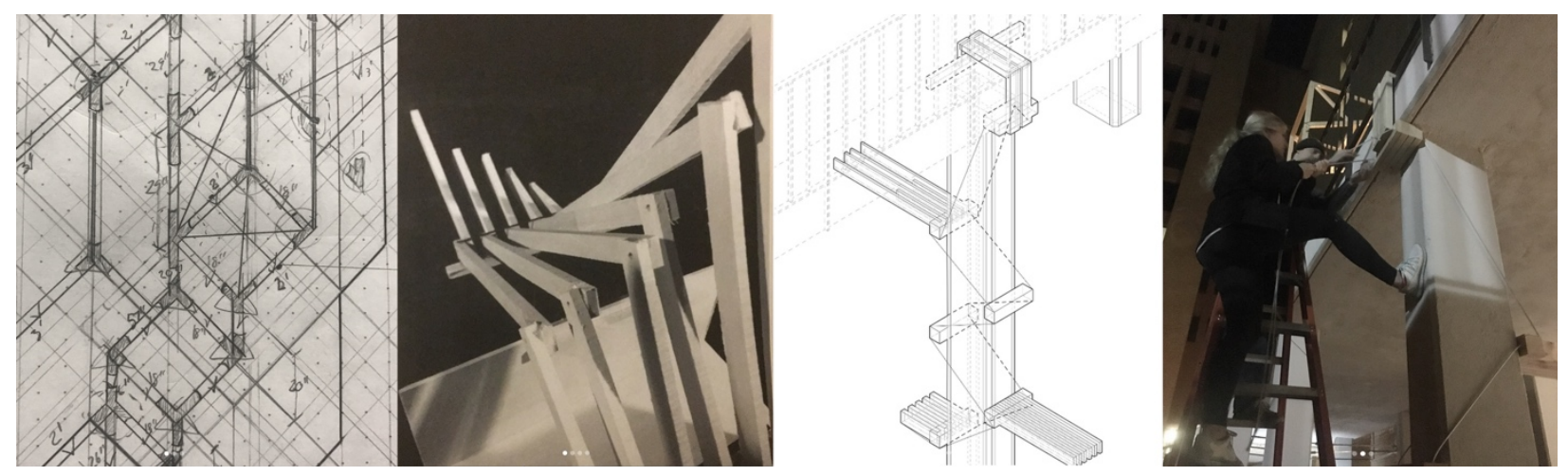

Figure 4. Example of the full-scaled installation and design process within Building Technology II course, where student groups design and install tectonic structures within the Architecture Building courtyard. Source: Various student work, second-year, fall 2017.

To test these structural capacities, physical models are used to test the limits of materials - moving beyond simple mathematics and into testing to failure of specific structural elements and systems, before moving into digital modelling of the designed structural elements from their studio to test efficacy of their ideas. The final projects, full-scaled installations within the courtyard of the architectural school puts this knowledge on display for the entire school and university and serves as a culminating juncture of integrating material ecology, fundamental structural knowledge and some aspect of solar mitigation and solar collection within a tectonic construct at full scale. A simple requirement of maximum material 
budget and weight ensures that the students are thoughtful with their designs and premeditated with the material and types of assembly that they employ.

\section{Third-Year and Course Integration}

During the third-year, the curriculum continues to build in complexity and integration while introducing two important architectural elective courses that are open to the students. These allow students to focus their discovery while beginning to position themselves and their work within the larger architectural canon. The reflexive ability for these courses to integrate design directly into lecture courses that teach sustainability, history, urban ecology, or theory, students can learn from implementing these ideas into their design studios - where things can be integrated and tested. Specifically, within the final Building Technology course, students are asked to investigate in full detail an architectural precedent from detail, construction, atmospheric qualities and material geographies. Synthesizing this technical knowledge to design thermal, atmospheric and climatic mitigating factors on building envelopes while designing passive (and massive) design that allow for open exchange with the surrounding environment. Studio projects are public and urban in scope to allow this open exchange to occur at a climatic and human level. This strives to emphasize that buildings must exchange with the surrounding environs, and allow for more nuanced, open systems that incorporate ecological concerns beyond the simplistic anthropocentric focus of architecture.
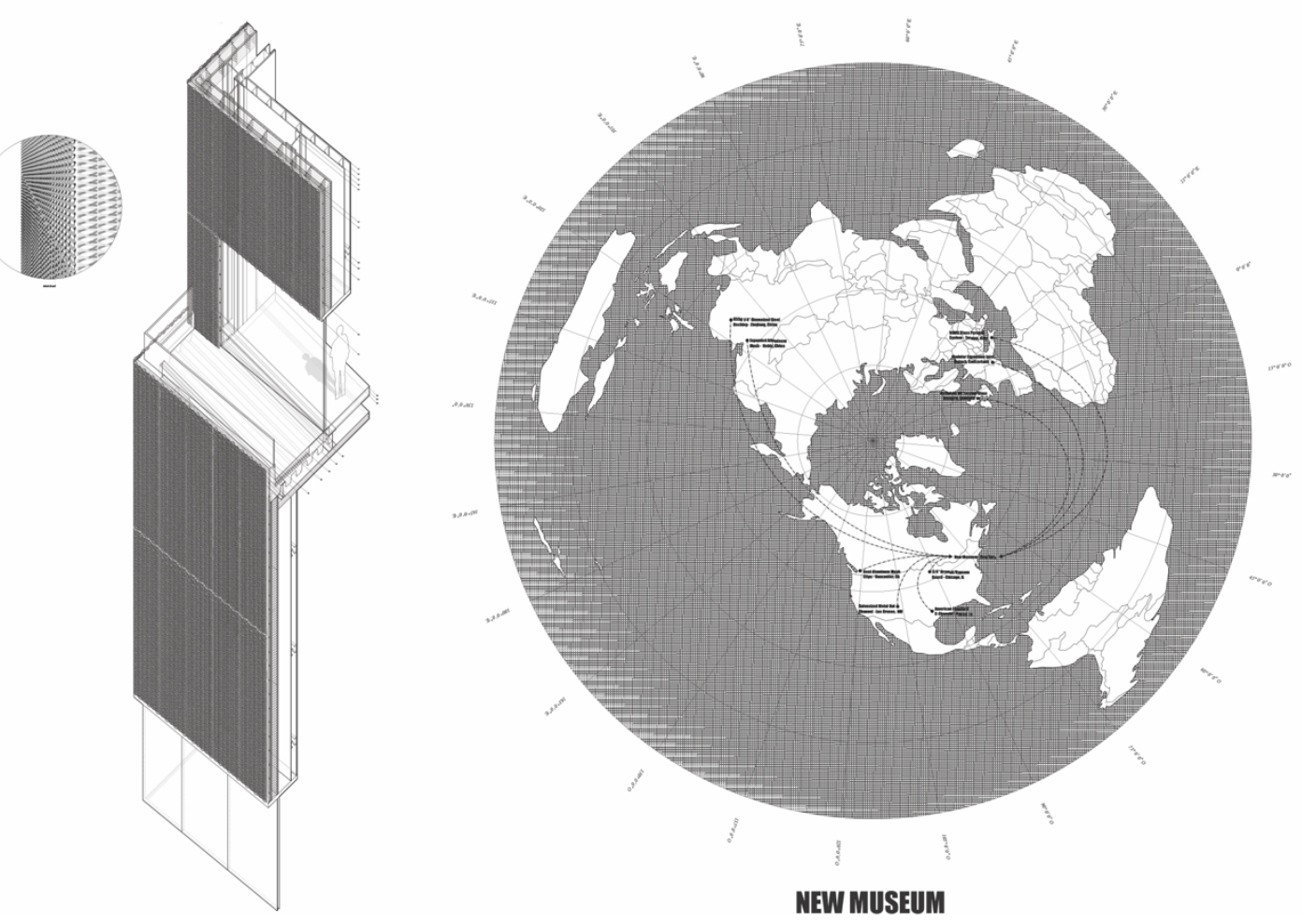

Figure 5. Detailed sectional oblique diagram and material geography diagram of SANAA's New Museum demonstrating the primary architectural materials and sourcing, from the detail to the global. Source: G. Livingston + W. Williamson, third-year, spring 2019.

For example, the design prompt was for a special collections library and archival space within a downtown city plot. Studios worked with urban planners, environmental engineers to negotiate the delicate balance between environment and intervention. The public program necessitated the control of natural light, humidity, and resilience in the event of an extreme weather event that seems to come more frequently over the past decade. Questions relevant to our specific area are rising temperatures, productive landscapes, desertification, heat-island effects and potential water shortages. These concerns are carefully woven into the studio brief, so as not to appear heavy-handed, but to create a climate for addressing these 
important issues. What it means to design architecture for our precise climate, and a changing one? How can material and energy conservation be understood and utilized (this is tied directly to a shared assignment within the Environmental Controls class)? How can architects design productive, ecological buildings that are performative? Studios are encouraged to increase the audience of these studios by inviting at least one outside consultant from beyond the architecture building for design reviews.

\section{Integrative Studio}

In the final semester of the four-year undergraduate degree students will complete an integrative studio. These studios currently occur at the beginning of the graduate sequence, which during the last five years we have made efforts to better coordinate the outputs of these studios through the design of the inputs. First, these studios are taught by two professors while a second course, integrative building modeling is taught by a third professor. Each of these professors has a specific strength which they bring to bear on the studio - the integration is not simply in the comprehensive nature of the design resolution, but the three professors integrate through a series of joint presentations and exercises. The coordinating design instructor sets the programmatic and defines the overall schedule for each of the course components. The second design instructor brings more structural and material acumen to the discussion and is involved in initial discussions of siting, climate and early schematic iterations. The technical lecture course is brought in during three distinct moments within the design process. During the initial massing phase, climate analysis is done using computational tools to convey ramifications of the students ideations.

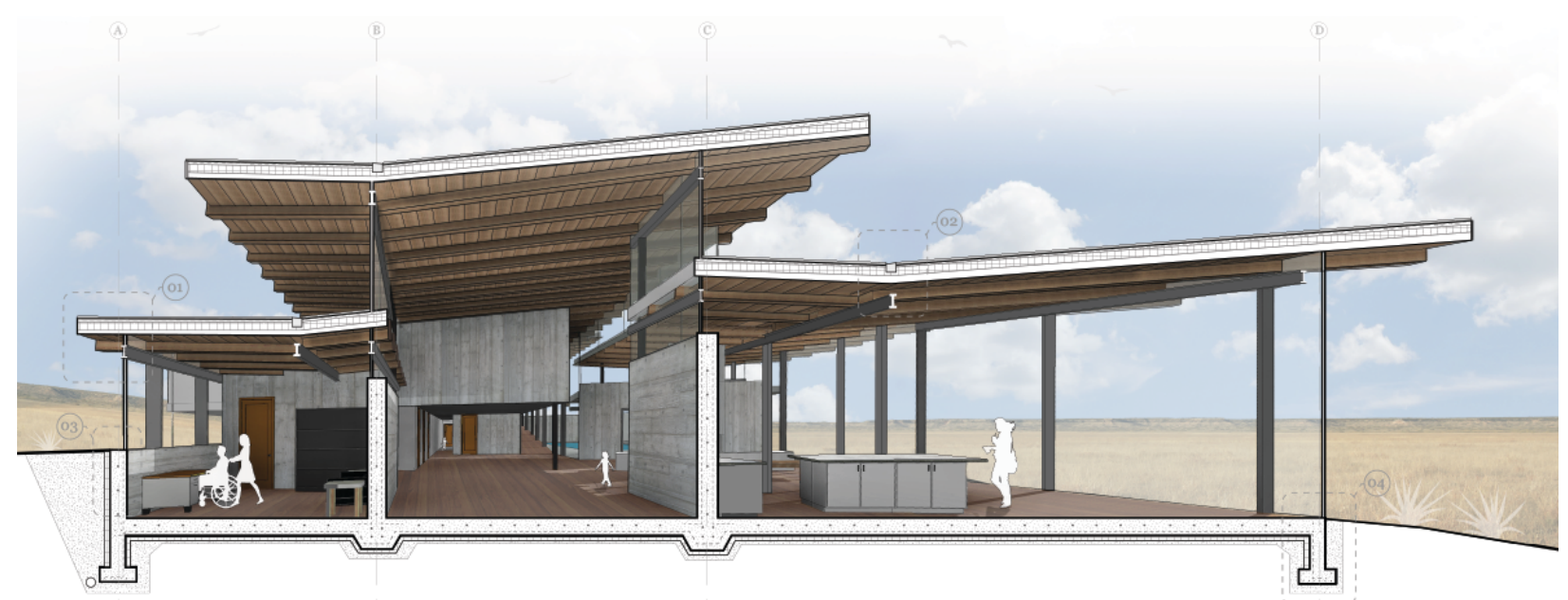

Figure 6. Detailed sectional perspective of integrative design studio exhibiting the ecological tuning of spatial, material and detail. Source: A. Gray, integrative studio, spring 2019.

Instead of allowing loose coordination of the design prompts, the prompts are specifically designed around specific performance criteria such as thermal, ventilation or lighting constraints. Projects are required to be in open dialogue with their surroundings - both socially and environmentally. One specific semester of integrative studio each group was given a specific artist and concept, which they then needed to design a building to perform for that specific technological objective. For example, various groups were assigned Olafur Eliasson + House of Light, Nancy Holt + House of Natural Ventilation, Robert Irwin + House of Natural Light, Andy Goldsworthy + House of Waterproofing, or Dan Flavin + House of Artificial Illumination, and so on. Each student would study the local conditions of a specific site to then tune their designs to performative feature. After a series of physical models and programmatic planning ideas, preliminary designs are input into Revit where preliminary analytical models are used for specific scenarios through parametric comparisons. By the middle of the semester, large scale (1/2": 1'-o") models are used to test their designs using smoke-tests, heliodons, buckets of water, etc. to assess how gas, light 
or liquid would interact with the specific envelope, mass or programmatic function to celebrate the performance.

These models continue to be updated, refined and crystallized as the projects are developed. The integrated building modelling is used to calculate carbon totals and materials used at the midterm review to begin discussing how much concrete, steel, wood, glass is being used, researching the material geographies and $\mathrm{CO} 2$ balancing to determine the true cost of their design choices. Giving each student a carbon budget for the project allows students an opportunity to truly test idealized notions of ecology, total life cycle costs of materials, energy usage and environmental ramifications of their designs. Models are continually updated and structural, mechanical, plumbing and site information is refined based on these midterm calculations as the students finalize their designs for the final presentations.

The importance of this semester is assimilation of knowledge through a complete project that can be used to assess the student's overall ability to combine several sets of information; from representational tools to whole building integration. Due to the scope of the project and the desire for a more comprehensive final project the scale of the buildings is kept around 12,000 square feet and projects are developed in teams of two. Throughout the semester, local engineers, architects, ecologists, and sustainability specialists are brought in from across the University and state to assist in elevating the discussions beyond the limited scope of any one professor (or department). Based on feedback that we have received over the three semesters that this course has been offered, the students response has mostly been positive. In addition, the feedback from employers and graduates is that this course has better prepared them for professional practice. Their ability to work through ideas at a variety of different scales and levels of complexity and collaborate with a fellow student and a variety of professionals and professors has strengthened their aptitude to bring ideas through a full-fledged design processes.

\section{PEDAGOGICAL OUTCOMES}

Previous to the curricular change, the studio sequence was coordinated spuriously. While we have yet to see the full effects of this evolving, major curricular overhaul move through the undergraduate, even in the five years since implementation students have begun to reap rewards. Students are able to consider their design decisions beyond notions of simple objects without consequence or consideration beyond the limits of the exterior surface while better understanding extensions of architectural design within specific environments. The influence of this tighter curricular structure, with a broader understandings of architecture as field of that impact dialectical structures of the universal and particular, social and cultural, environmental and cultural, speculation and pragmatism, as well discipline and the profession. Initiating real connections beyond the walls of the College of Architecture whilst creating cross-campus links to other disciplines are essential. One aspect of this hope to increase interdisciplinary dialogue across the University through the addition of a new certificate and Masters of Science program to broaden the discussion within the College of Architecture to related fields of Landscape, Interior and Engineering, but also Policy, Health, Ecology, Biology and Policy. Creating opportunities for graduate students from diverse fields to cross-list and take elective courses and collaboration design studios within the College of Architecture has already enlivened the discourse within the College and beyond. One such studio that exhibits excellence within this multidisciplinary and ecological framework offered during the spring of 2016 where graduate students were asked to design projective architectures for the 20[1]6/0 : LA Water Tower.

Employing a multi-disciplinary approach from the beginning involved a structural engineer from Ove Arup, a façade specialist from Dallas, and an architect from Renzo Piano Building Workshop to several design studio critiques throughout the semester. Likewise, a visit to Morphosis Architects and several canonical buildings on a research trip to Los Angeles to afford the students an understanding of the multiple fronts of Los Angeles' design pasts and futures. One of these students was awarded First Prize in the 2016 ACSA/AISC Steel Tall Building Competition for his studio project VertiCali. The project went beyond the notion of simply creating a singular, multi-use building and was rewarded for integrating a vertical greenhouse, aquaculture and community farming infrastructure for the citizens of Eastern Los Angeles while re-connecting and re-greening the Los Angeles River. An ecological and integrated 
curricular structure helped him frame these larger questions of what architecture is, and what it can be beyond an anthropologically-scaled sustainability.
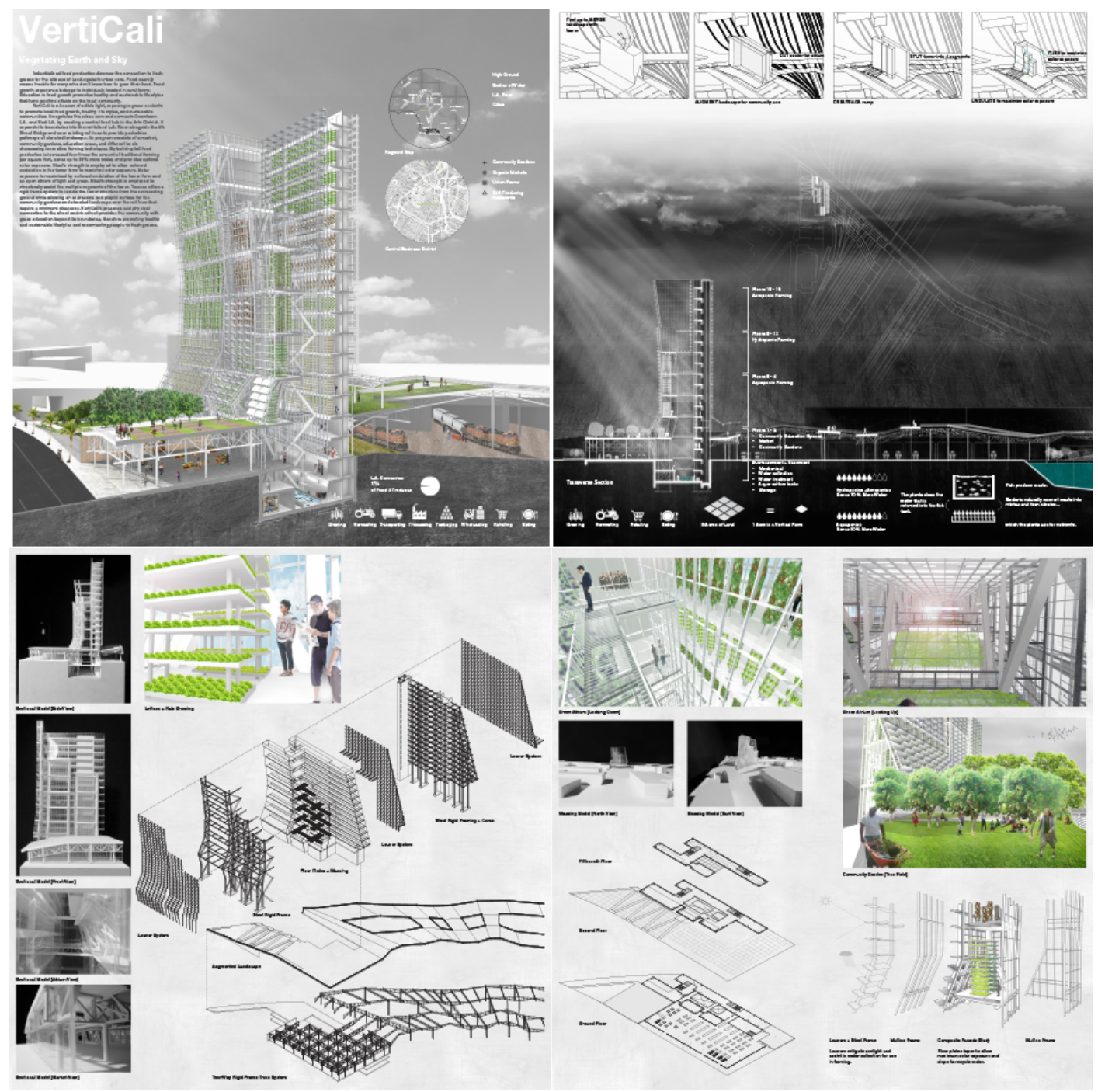

Figure 7. Final submission for the 2016 ASCA/AISC Steel Competition, awarded First Prize in the "Tall Building Category", from Texas Tech University Topical studio taught by the author. Source: M. Ramos, graduate, spring 2016.

By tuning buildings to the context and climate, students are able to take control of their design decisions more completely. The ability for students to understand the larger issues from the territory down to a molecular understanding of the materials that they might employ allow for an enriched design process. Fully embracing the technological and more scientific aspects of building design will allow for these future architects to drive the design of buildings that will be better tuned to the climates and ecologies they are within. With the desire for a more holistic view of the world will lead to richer milieus that endure beyond the isolation of modernism. Further shifting of the pedagogical discourse beyond its current stasis could truly be radical and offer new possibilities in understanding the larger ecologies in the desire to design within a changing climate. 


\section{REFERENCES}

Colomina, Beatriz, et. al. 2012. "Radical Pedagogies in Architectural Education." The Architectural Review, September 28, 2012. Retrieved August 11, 2019. www.architectural-review.com/today/radicalpedagogies-in-architectural-education/8636066.article

Dennehy, K.F. 2000. "High Plains regional ground-water study: U.S. Geological Survey Fact Sheet FSo91-OO" (PDF). USGS. Accessed July 31, 2019. https://pubs.er.usgs.gov/publication/fsog100

Graham, James, ed. 2016. "The Universals and Particulars of Climate." Climates: Architecture and the Planetary Imaginary: 21-33. Germany: Lars Müller Publishers.

La Roche, Pablo. 2018. Rethinking the Future of Sustainable Design. Design Intelligence Quarterly 3Q 2018. Accessed June 18, 2019. https://www.di.net/articles/rethinking-future-sustainable-design/

Latour, Bruno, 2018. Down to Earth, Politics in the New Climate Regime. English Edition. Medford, MA: Polity Press.

MacKay-Lyons, Brian. 2008. Ghost, Building and Architectural Vision. New York, NY: Princeton Architectural Press.

NRC, 2010. "Adapting to Impacts of Climate Change." America's Climate Choices: Report of the Panel on Adapting to the Impacts of Climate Change. National Research Council. Washington, DC: The National Academies Press.

Olgyay, Victor, 1963. Design with Climate, Bioclimatic Approach to Architectural Regionalism. Princeton, NJ: Princeton University Press.

Pérez-Gómez, Alberto, 2016. Attunement Architectural Meaning after the Crisis of Modern Science. Cambridge, MA: The MIT Press.

Pickens, Buford L. 1949. Regional Possibilities in Design and Construction, Journal of Architectural Education (1947-1974), Vol. 4, The Regional Meeting of the Southeastern Schools of Architecture (Winter, 1949), p. 20-23. Taylor and Francis, JSTOR (1423972)

Schafer, Ashley and Amanda Reeser Lawrence, eds. 2011. Beyond Green. PRAXIS: Journal of Writing + Building, Issue 13 - Ecologics, Boston, MA: PRAXIS

Srinivasan, Ravi and Keil Moe, 2015. The Hierarchy of Energy in Architecture. New York, NY: Routledge. 